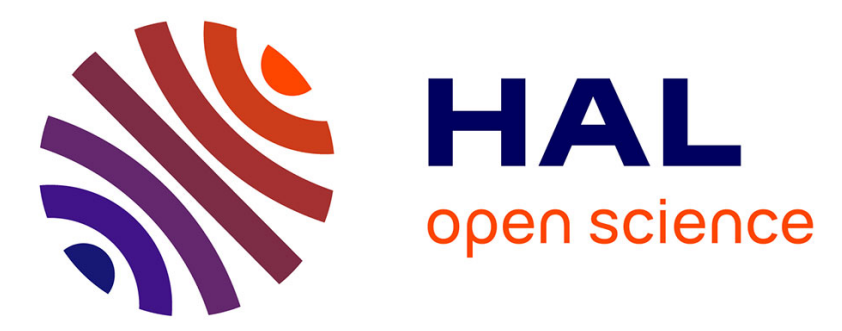

\title{
How Newly Acquainted Dyads Develop Shared Stereotypic Impressions through Conversation
}

\author{
Janet B. Ruscher, Elizabeth L. Cralley, Kimberly J. O'Farrell
}

\section{To cite this version:}

Janet B. Ruscher, Elizabeth L. Cralley, Kimberly J. O'Farrell. How Newly Acquainted Dyads Develop Shared Stereotypic Impressions through Conversation. Group Processes and Intergroup Relations, 2005, 8 (3), pp.259-270. 10.1177/1368430205053942 . hal-00571607

\section{HAL Id: hal-00571607 https://hal.science/hal-00571607}

Submitted on 1 Mar 2011

HAL is a multi-disciplinary open access archive for the deposit and dissemination of scientific research documents, whether they are published or not. The documents may come from teaching and research institutions in France or abroad, or from public or private research centers.
L'archive ouverte pluridisciplinaire HAL, est destinée au dépôt et à la diffusion de documents scientifiques de niveau recherche, publiés ou non, émanant des établissements d'enseignement et de recherche français ou étrangers, des laboratoires publics ou privés. 


\title{
How Newly Acquainted Dyads Develop Shared Stereotypic Impressions through Conversation
}

\author{
Janet B. Ruscher, Elizabeth L. Cralley and Kimberly J. \\ O'Farrell \\ Tulane University
}

\begin{abstract}
This study investigated how feelings of closeness at initial acquaintance encourage the development of shared stereotypic impressions of others through conversation. At least early in a relationship, closer dyads may be especially inclined to get along with one another. In order to satisfy this goal, they should focus their conversations around easily agreed upon stereotypic attributes and spontaneously express agreement about those attributes. As a consequence, the shared impressions that they form should be relatively stereotypic. In this study, closeness was manipulated in previously unacquainted college-age dyads, who then discussed their impressions of an elderly woman. Closer dyads allocated more discussion time to stereotypic attributes, expressed agreement about those attributes, invoked stereotypic exemplars, and ultimately formed more stereotypic shared impressions. The discussion considers study limitations and possible boundary conditions of the effects, as well as implications for the transmission of outgroup stereotypes during socialization to a new ingroup.
\end{abstract}

KEYWORDS conversation, shared impressions, stereotyping

NEWLY acquainted individuals juggle a number of simultaneous social tasks during their initial conversations. They endeavor to paint favorable self-portraits, try to ascertain reciprocity of feeling, and try to become better acquainted. Meanwhile, in addition to these challenges of mutual impression formation, newly acquainted individuals must negotiate the tasks that brought them together in the first place: tasks whose explicit goals are often not mutual impression formation. Newly acquainted individuals may, for example, need to navigate a job training session or render a decision as a jury or as an expert panel. Perhaps more commonly, newly acquainted individuals may be the novice members of an established group who need to form shared impressions of higher status members, of veteran peers, or of outgroup members. The present paper focuses on how newly

\section{Author's note}

Address correspondence to Janet B. Ruscher, Department of Psychology, Tulane University, New Orleans, LA 70118, USA

[email: ruscher@tulane.edu] 
acquainted individuals approach this important task of shared impression formation during their initial conversations. Specifically, we demonstrate that when newly acquainted dyads feel close to their partners, they are prone to develop stereotypic shared impressions of outgroup members.

\section{Shared impression formation through conversation}

A shared impression involves a consensual understanding of what individual members of the group apparently believe, as well as an understanding about what the group as a whole believes. Upon encountering a new person, group members initially may presume some degree of consensus (e.g. Marks \& Miller, 1987), especially if the group members hail from similar backgrounds. Even so, if the target is minimally relevant, group members will communicate in an effort to confirm just how much consensus exists (Ruscher, Hammer, \& Hammer, 1996). This shared sociocognitive process mimics how individual perceivers initially work toward confirmatory categorization of minimally relevant targets, as described by the continuum model of impression formation (Fiske \& Neuberg, 1990). For small groups, confirmation of a shared impression might be a brief nonverbal exchange, an agreeing nod in response to a group epithet, or a longer conversation about the target. For example, after learning that a mutually known target possesses a social stigma, acquainted dyads avidly discuss their recollections of the target's behaviors and make inferences about the target (Ruscher \& Hammer, 1994). In revising their impression of the now stigmatized target, acquainted dyads try to judge the extent to which they hold a shared impression. Moreover, they discuss how well the stigma fits with other target characteristics and eventually come to use the stigma as the central organizing characteristic of their shared impression.

This consensual understanding is facilitated by focusing conversation around stereotypic attributes of the target. When acquainted dyads explicitly (Ruscher et al., 1996) or implicitly
(Ruscher \& Hammer, 1994) need to reach a consensus about a target person, they allocate a disproportionate amount of their discussion time to stereotypic attributes. Because stereotypes are implicitly shared among culturally similar people, stereotypic information is easily understood and, indeed, is recognized as the kind of information upon which people quickly can agree (Ruscher \& Duval, 1998). Interestingly, this preference for discussing shared information also is evident in studies of group decision-making and problem solving (e.g. Stasser \& Titus, 1985). With both shared impression formation and group decisionmaking, people presumably want to develop a common ground understanding in order to relate better to one another (Wittenbaum \& Stasser, 1996). With impression formation among consensually focused acquainted dyads, the common ground understanding that develops is relatively stereotypic and is related directly to focus on stereotypic information. Moreover, that development of shared stereotypic impressions is related directly to dyads' spontaneous agreement about that stereotypic information (Ruscher et al., 1996).

Beyond agreeing about and allocating time to stereotypic attributes, consensually focused dyads produce conversations whose content is relatively stereotypic. For example, people who discuss outgroup members often introduce stereotypic exemplars into their conversations. In some cases, these exemplars appear to serve as illustrations of the stereotypic qualities of the outgroup (e.g. Harasty, 1997; van Dijk, 1988). Indeed, telling a story about a particular outgroup member's apparently insensitive or even criminal behavior may suggest that the entire outgroup possesses such qualities (cf. Henderson-King \& Nisbett, 1996). In other cases, stereotypic exemplars are invoked as a means of comparison. The newly encountered target reminds the conversing dyad of prototypical exemplars: an elderly target is reminiscent of one person's crotchety grade school teacher, a target with alcoholism resembles the consistently drunk 'regular' at a local pub, a gay target evokes thoughts of a stereotypically flamboyant character on television. These 
stereotypic exemplars are invoked particularly when consensus is sought (e.g. Ruscher \& Hammer, 1994; Yost, 1995), which suggests that the stereotype is accessible and is being applied to the target. Indeed, people who hear others invoke stereotypic exemplars of a group increase their own stereotyping of subsequently encountered members of that target group (Duval, Ruscher, Welsh, \& Catanese, 2000), so spontaneously introducing stereotypic exemplars into conversation likely is associated with stereotype accessibility.

\section{New acquaintances}

For newly acquainted dyads, the development of shared stereotypic impressions presumably would be encouraged by consensual focus. But what besides explicit instructions to reach consensus might especially encourage newly acquainted dyads to seek consensus and, consequently, to stereotype an outgroup member? One likely possibility is the extent to which the newly acquainted dyad members feel close to one another and experience reciprocal liking. At least in the early stages of a relationship, feelings of closeness might encourage desires for consensus and similarity of opinion. For example, people report greater attraction to strangers who share their evaluative perceptions of other targets (Craig \& Duck, 1977). Indeed, relationships in their formative stages are marked by mutual enhancement, agreement, and similarity (e.g. McCarthy \& Duck, 1976; cf. Swann, de la Ronde, \& Hixon, 1998). Mutual enhancement goals can be met by focusing on information that is shared among group members, because that information can be validated by other group members (Wittenbaum, Hubbell, \& Zuckerman, 1999). By extension, one might expect that newly acquainted dyads who feel close to one another would tend to agree about their impressions of others and would focus on implicitly shared information.

Of course in naturalistic settings, dyads who experience some type of initial bond might share other qualities that could encourage stereotyping, besides feelings of closeness. For example, dyad members recently might have both experienced a self-esteem threat, and thus temporarily might have bonded together because misery loves miserable company. A self-esteem threat might encourage them to stereotype (and possibly to derogate) a target person (e.g. Fein \& Spencer, 1997), thereby adding the additional purpose of self-esteem restoration, beyond the desire to get along with an attractive other. Alternatively, existing close dyads might be especially similar with respect to culture or ethnicity and, on average, hold exceedingly similar stereotypes of outgroups; such dyads might form more shared stereotypic impressions of an outgroup member simply because they already share more overlap in impressions than less close dyads. To isolate initial feelings of closeness from these (admittedly interesting) factors that sometimes co-vary with closeness in natural settings, we manipulated closeness among half of the previously unacquainted dyads in the present study, adapting a closeness-generating procedure designed by Aron, Melinat, Aron, Vallone, and Bator (1997).

\section{Summary and hypotheses}

In sum, recent acquaintances who feel close should be motivated to get along with each other. Focusing conversation around implicitly agreed upon (i.e. stereotypic) attributes and expressing agreement with such information should help meet this goal of a smooth mutually rewarding interaction. The conversations as a whole should be more stereotypic, including references to stereotypic exemplars. As a consequence of focusing on stereotypic attributes, the shared impressions formed should be relatively stereotypic. We therefore predicted that, compared to less close dyads:

(a) closer dyads would allocate more discussion time to stereotypic attributes;

(b) closer dyads would express verbal agreement about stereotypic attributes;

(c) closer dyads would invoke more stereotypic exemplars;

(d) closer dyads would hold conversations that were rated as more stereotypic; 
(e) closer dyads would form more stereotypic shared impressions.

Finally, we also examined a mediational model, predicting that:

(f) the relation between closeness and shared stereotypic impressions would be mediated, at least in part, by discussion of stereotypic attributes.

\section{Method}

\section{Participants}

Thirty-two previously unacquainted same-sex dyads (4 male; 28 female) participated in exchange for extra credit in their psychology courses; participants were between 19 and 23 years of age. Dyads were assigned randomly to either the less close or closer condition. Samesex dyads were used to increase the likelihood of similar stereotypic expectations within a dyad (i.e. stereotypes of elderly women should be more similar in same-sex than mixed-sex dyads). The data of two female dyads who failed to follow instructions were discarded, leaving 15 dyads in each condition.

\section{Procedure}

Experimenters scheduled two previously unacquainted same-sex college students to participate together, drawn from several large lower-division courses. When both dyad members arrived, a female experimenter explained that instructions for the entire experiment would be provided on audiotape; this procedure allowed experimenters to remain unaware of the closeness condition and also provided uniform procedures for all dyads. After obtaining informed consent, the experimenter activated the audio-cassette player and the video-camera, then left the room.

Closeness manipulation The female voice on the audiotape instructed participants to open their first set of folders, inside of which seven questions were written. These questions were borrowed from Aron et al.'s (1997) procedure for manipulating dyadic closeness. The original Aron et al. procedure for generating closeness requires approximately 45 minutes, and involves dyads in the closer condition to ask questions that are intimate and self-disclosing, such as 'What is the greatest accomplishment of your life?' and 'Why do you consider it to be your greatest accomplishment?' In Aron et al.'s less close condition, dyads ask each other trivial questions.

Informal pretesting as well as two previous studies in our lab (O'Farrell \& Ruscher, 2000) verified that our shorter procedure, requiring only 6-7 minutes, could be successful in creating different levels of closeness. The shorter procedure lent itself to the typical 45 minute study participation time (i.e. a class period), allowing dyads to perform the subsequent tasks and participate in a debriefing interview during the time allotted (cf. Sedikides, Campbell, Reeder, \& Elliot, 1999). In this adapted procedure, the tape-recorded voice instructed dyads in the closer condition to become better acquainted by orally sharing their responses to each question from a subset of the intimate questions from Aron et al.'s (1997) longer procedure; these seven questions were enclosed in the aforementioned folder. For dyads in the less close condition, the tape-recorded voice instructed dyads to write their responses to these same questions on paper, purportedly to allow the researchers to know more about them. This control condition was included rather than Aron et al.'s shared trivial questions in order to keep less close dyads cognitively and affectively comparable to closer dyads. Thus, whereas Aron et al.'s (1997) original procedure confounds particular questions with condition (and possibly the moods or depth of thought encouraged by the questions), the present procedure confounds the audience for the responses (i.e. the other participant versus the researchers). After providing the instructions for the requisite condition, the audiotape then paused for seven minutes to allow participants to respond to the questions.

Stimulus person The audiotape next informed dyads that they would hear a description of a person, and that together they would discuss that person later in the study. Dyads then heard 
one of two descriptions of an elderly retired woman, used in previous research (Duval et al., 2000). Alternate versions were used for purposes of generalizability. Each description conveyed two attributes that were stereotypic and two attributes that were counterstereotypic with respect to stereotypes of elderly people. Pretested stereotypic attributes comprised adheres to strict routines, has wisdom of experience, opinionated, and moves around slowly $(M=2.29$ in stereotypicality and $M=0.16$ in valence on +3 to -3 scales) and counterstereotypic attributes comprised politically liberal, computer buff, makes impulsive decisions, and has a mind like a steel trap (stereotypicality $M=-2.40$; valence $M=0.16$ ).

After presenting the description, the audiotape instructed dyads to discuss their impressions of the person just described. Once 2.5 minutes had elapsed, the audiotaped voice requested that dyads stop their conversation and individually complete, without consultation, the surveys in their next folder. Surveys required participants to rate the target on four items associated with stereotypes of elderly people (slow to learn; forgetful; incompetent; foolish) used in previous research (Duval et al., 2000; Ruscher \& Hurley, 2000); scores on these items were averaged as a single index of resulting stereotypic impressions (Cronbach's alpha = .70). Surveys also included two items from Aron et al. (1997) and seven items from Zaccaro and McCoy (1988) that assessed perceived closeness and interpersonal attraction. Scores on these nine items were averaged to form a check on the closeness manipulation $($ Cronbach's alpha $=.77)$. These items included 'To what extent would you enjoy working with your partner again?' and 'I wanted my partner to like me'. All survey items were presented along 11-point Likert-type scales. After completion of all tasks, dyads were probed for suspicion and debriefed. Dyad members finally were given an opportunity to request erasure of their videotape; no one made such a request.

Data from the videotapes Following previous procedures (e.g. Ruscher \& Hammer, 1994), a coder unaware of the experimental condition determined whether dyads explicitly discussed the stereotypic or counterstereotypic attributes, or made comments irrelevant to the stereotype. Stereotype-irrelevant comments included references to the speaker who described the target, theories about other qualities of the target (e.g. marital status; occupation), and irrelevant interchanges (e.g. comments about the videocamera). Although potentially interesting, hypotheses about these aspects of conversation were not generated a priori, so they were not analyzed. A second coder unaware of condition independently coded a random third of the protocols (totaling 299 comments). Cohen's kappa indicated good agreement for these three designations $(\kappa=.71)$, with particularly rare disagreement on whether discussed attributes were stereotypic or counterstereotypic $(\kappa=.96)$. Using the first coder's designations, the number of seconds allocated to counterstereotypic and stereotypic attributes were recorded with a stopwatch.

Also following previous procedures, the first coder counted the dyads' references to specific exemplars (e.g. 'She reminds me of my grandmother, who has a hard time getting used to modern times'), verbal expression of agreement about those attributes (e.g. 'Yeah, you're right'), and comments that were neither exemplars nor agreement. The second coder evinced a similar understanding of whether comments were exemplars, agreement, or other comments $(\kappa=.84)$; coders never confused exemplars with agreement $(\kappa=1.00)$.

Finally, the first coder made a global assessment on a 5-point scale of how much the entire conversation stereotyped the elderly target, with higher scores reflecting greater stereotypicness. This assessment simply provided a more holistic view of the conversation, in recognition that time allocation to target attributes, invoked exemplars, and agreement may not have captured fully the stereotypicness of the conversation. The second coder made ratings on one-third of the conversations $(N=10)$; ratings of the coders were highly correlated $(r(8)=.82)$ and average ratings made by the two coders were statistically indistinguishable $(F<1)$. 


\section{Results}

A two-person conversation is by nature dyadic, alternating turns of listening and speaking, so such data were recorded at the dyad level. For the questionnaire data, intraclass correlation coefficients (Kenny, 1988) indicated that scores of dyad members were consensual and not independent (manipulation check $=.49$; stereotyping index $=.52$, both significant at $p<.01$ ). The dyad therefore was used as the unit of analysis for these data as well. All means are reported in Table 1; correlations among the independent variable, manipulation check, and dependent variables are reported in Table 2.

\section{Manipulation check}

Data from the manipulation check were analyzed with a one-way between-groups analysis of variance (ANOVA), using closeness as the group factor. As expected, dyads in the closer condition $(M=9.06)$ reported feeling closer to and greater attraction toward their partners than did dyads in the less close condition $(M=$ 8.12) $\left(F(1,28)=7.11, p<.02, \eta^{2}=.203\right)$.

\section{Conversation data}

The number of seconds that dyads allocated to discussing the target's attributes were submitted to a $2 \times 2$ closeness (less, more) by attribute stereotypicness (stereotypic, counterstereotypic) mixed model ANOVA with repeated measures on the last factor. Closeness did not predict

Table 1. Discussion time, exemplar use, and agreement, as a function of closeness and attribute stereotypicness

\begin{tabular}{lccc}
\hline & \multicolumn{2}{c}{ Closeness } & Simple \\
\cline { 2 - 3 } & Lower & Higher & effect \\
\hline Time & & & \\
$\quad$ Stereotypic & 19.10 & 31.92 & $p<.05$ \\
$\quad \begin{array}{l}\text { Counterstereotypic } \\
\text { Agreement }\end{array}$ & 24.43 & 14.84 & $p<.10$ \\
$\quad \begin{array}{lll}\text { Stereotypic } \\
\quad \text { Counterstereotypic }\end{array}$ & 0.99 & 2.01 & $p<.05$ \\
$\begin{array}{l}\text { Exemplars } \\
\quad \text { Stereotypic }\end{array}$ & 0.04 & 0.50 & $p<.10$ \\
$\quad$ Counterstereotypic & 0.54 & 0.65 & $p<.20$ \\
\hline
\end{tabular}

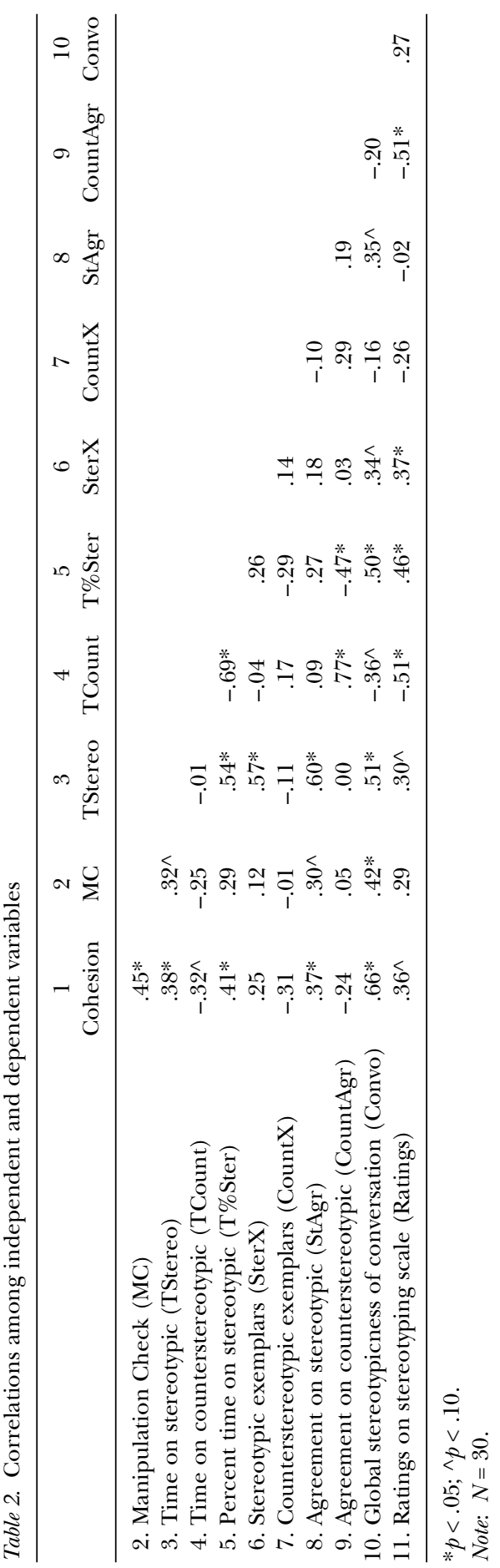


differences in overall focus on stereotyperelevant attributes $(F<1$, less close $M=43.53$; more close $M=46.76)$. Instead, the ANOVA detected only the predicted closeness-bystereotypicness interaction $(F(1,28)=9.09, p<$ $\left..005, \eta^{2}=.245\right)$. As seen in Table 1 , closer dyads focused more on stereotypic attributes than did less close dyads; closeness did not significantly predict differential focus on counterstereotypic attributes. Discussion time allocation therefore provides the first piece of evidence that, at least at initial stages of a relationship, increased feelings of closeness can encourage stereotyping.

Content analyses lend insight into the nature of these conversations. Because increased time discussing the target's attributes conceivably provided dyads with more opportunities to agree with one another and to invoke exemplars, time allocated to discussing target attributes was entered as a covariate in the $2 \times 2$ closeness-by-stereotypicness analyses on these dependent variables. For agreement, the analysis of covariance (ANCOVA) detected only the closeness-by-attribute interaction $(F(1,27)=$ $\left.5.56, p<.03, \eta^{2}=.171\right)$. As seen in Table 1 , closer dyads agreed more when discussing stereotypic attributes than did less close dyads. As expected, then, closer dyads apparently developed their common ground along stereotypic dimensions.

The ANCOVA on invoked exemplars also detected the closeness-by-stereotypicness interaction $\left(F(1,27)=8.104, p<.008, \eta^{2}=.231\right)$. As shown in Table 1, closer dyads tended to generate more exemplars around stereotypic attributes than counterstereotypic attributes, whereas less close dyads evidenced little preference. This finding would suggest that, as expected, closer dyads found the target reminiscent of known stereotypic instances.

Finally, global ratings of how much the conversation as a whole appeared to stereotype the elderly person were submitted to a one-way ANOVA. Closer dyads $(M=3.87)$ produced more stereotypic conversations than did less close dyads $(M=2.60)(F(1,28)=21.97, p<.001$, $\left.\eta^{2}=.44\right)$. Thus, a more holistic view of the conversation was consistent with what emerged through analyses of discussion time, stereotypic exemplars invoked, and agreement about stereotypic attributes. These ratings also correlated significantly with time allocated to discussing stereotypic attributes, and marginally with the other indicators of stereotyping through conversation (see Table 2).

\section{Resulting impressions}

As noted above, dyads' subsequent impression ratings were not independent (interclass correlation $=.52$ ), indicating that the impressions formed were shared. Dyads' average ratings of the four stereotypic attributes, made subsequent to their conversations, were submitted to a one-way ANOVA. As expected, the impression ratings of closer dyads $(M=4.63)$ tended to be more stereotypic than those of less close dyads $(M=3.60)\left(F(1,28)=4.03, p<.055, \eta^{2}=.126\right)$.

Path analysis To what extent did the stereotypic processing during the conversation give way to stereotypic impressions? We examined the extent to which the closeness-stereotyping relation might be mediated by preferential focus on stereotypic attributes, using the procedures outlined by Baron and Kenny (1986). Three regression equations were estimated. First, closeness (less close $=-1$; more close $=+1$ ) marginally predicted the dependent variable of shared stereotypic impressions (standardized $\beta=.355, F(1,28)=4.03, p<.055)$. Second, closeness predicted the proposed mediator, percentage of time ${ }^{1}$ allocated to stereotypic attributes $(\beta=.41, F(1,28)=5.63, p<.03)$. Finally, when both closeness and time were entered as predictors, the effect of closeness on shared stereotypic impressions was reduced (closeness $\beta=.20, p<.29$; time $\beta=.38, p<.05$, $F(2,27)=4.37, p<.03)$. Given the small sample size, a bootstrap analysis was employed to test the indirect effect (Preacher \& Hayes, 2004; Shrout \& Bolger, 2002). Insofar as the confidence interval around the indirect effect contained zero, this analysis did not provide evidence for a significant indirect effect (point estimate unstandardized $b=.22 ; 95 \%$ confidence interval around $b-.04$ to $.60 ; N=30$; 10,000 bootstrap resamples). The failure to detect a significant indirect effect is addressed in the discussion. 


\section{Discussion}

Compared to less close dyads, newly acquainted college-age dyads who felt closer to one another focused their discussions around stereotypic attributes and agreed about those attributes. They also referenced stereotypic exemplars, held conversations that generally stereotyped the target, and formed shared impressions that were relatively stereotypic. Thus, at least at early stages of acquaintance, feelings of closeness apparently encourage people to find common ground bases for agreement. Stereotyping others during conversation appears to be one convenient basis for finding such common ground.

Given that stereotypes comprise shared social representations, both members possessed information to contribute to the conversation. That is, not only did both dyad members learn stereotypic information about the specific target, but they presumably also possessed stereotypes and exemplars of elderly persons. Discussing shared information is validating and mutually enhancing, allowing each dyad member to feel important and to see her or his views echoed by the other (Wittenbaum et al., 1999). These findings have profound implications for situations in which small groups are charged with rendering decisions about the target, above and beyond impression formation. Newly acquainted groups such as expert panels and juries may, at times, be motivated more by desires to get along than by accuracy goals. If so, they may focus on stereotypic features, and make decisions based on stereotypes. Even if accuracy goals are in place, groups sometimes use consensus as a proxy for accuracy (Ruscher et al., 1996). The consensuality of stereotypic information implies veracity, so stereotype-based judgments actually may appear justified. What everyone believes is seen as true, a phenomenon that Allport termed the illusion of universality (Allport, 1954/1989).

\section{Potential boundary conditions}

In a broad sense, dyads in the present study focused their discussions strategically to satisfy a social goal (cf. Schaller \& Conway, 1999).
Among these newly acquainted individuals, increased feelings of closeness encouraged focus on stereotypic attributes. Closeness alone may not suffice for effects, insofar as the converse may occur for well acquainted dyads who already feel close. Among previously acquainted dyads, closeness predicts increased disagreement about a potentially stereotyped target's attributes, and predicts the formation of more complex (and essentially less stereotypic) impressions (Ruscher, Santuzzi, \& Hammer, 2003). Among good friends, closeness is not jeopardized by trivial disagreements and, indeed, some degree of unique opinion can be valued. But for both newly acquainted and established dyads, closer dyads appear to adopt whichever strategy is most likely to support the close relationship. That said, one can imagine situations in which stereotyping a third party would jeopardize closeness even for newly acquainted dyads, and would call for another strategy. For example, if strong norms prohibited expressing stereotypic beliefs about the third party's social group, dyad members might infer that closeness would be maintained by validating the nonprejudiced self-images presented by their partners. Social norms rarely prohibit the expression of stereotypic beliefs about elderly persons, but may be strong in other instances (e.g. European-Americans discussing an African-American target). In such cases, agreement among newly acquainted dyads might be sought regarding counterstereotypic attributes, to bolster closeness and validate non-prejudiced self-images. Thus, one boundary condition on the present effects may be the social acceptability of verbally expressing stereotypic views.

The social acceptability of verbally expressing stereotypic views could also underlie the extent to which individuals are likely to communicate specific attributes. Although equated for evaluative connotation (which is often confounded with stereotypicality), the stereotypic attributes in the present study conceivably were more communicable than the counterstereotypic attributes. Consistent with this reasoning, stereotypicality is associated with communicability for Canadians of European descent but 
not for ethnic minorities (Schaller, Conway, \& Tanchuk, 2002). Expressing stereotypic views of majority group members (e.g. white Canadians) is probably no more prohibited than expressing stereotypic views of elderly persons, so the stereotypic attributes in the present study likely were high in communicability. Indeed, communicable attributes may serve similar functions as stereotypic ones. Both may be likely to elicit agreement and be easily understood (Ruscher \& Duval, 1998), which would facilitate a smooth interaction.

As evident from the preceding discussion, an assumption of the present research is that newly acquainted individuals who feel close seek points of agreement. The current findings suggest that this goal may be achieved by focusing on stereotypic attributes, recognizing that communicable attributes or even counterstereotypic attributes sometimes might achieve similar goals. Although agreeing upon impressions of a third party individual may be sufficient to maintain closeness, a social target per se may not be formally necessary. Agreeing about a nonsocial object or sociopolitical issue, for example, also might maintain feelings of closeness and mutual attraction. On the other hand, agreeing upon impressions of a potentially stereotyped individual may be an especially powerful way to maintain feelings of closeness and mutual attraction. If circumstances elicit a high level of group differentiation or identity salience, for example, a sense of ingroup formation and 'we-ness' may enhance the desire to find points of agreement. In the present study, dyads were same-sex (predominantly female) college-aged students who were discussing an elderly woman. Consequently, for most of the dyads, age was the salient characteristic distinguishing them from the target. Our findings may be stronger than if identity salience was minimized (e.g. an elderly man and young woman discussing a middle-aged person) or if the discussion topic were a relatively uncontroversial social object (e.g. cola flavored with lemon). Stereotyping a third party target may be a viable method of maintaining closeness during early interaction, but it is unlikely to be the only method.

\section{Potential explanations for the nonsignificant indirect path}

According to expectation states theory (Berger, Fisek, Norman, \& Zelditch, 1977), people associate certain status characteristics with varying degrees of competence. Old age is a diffuse status characteristic, insofar as it sometimes implies the high competence of wisdom and experience (e.g. senators, emeritus faculty) or the low competence of feeblemindedness (e.g. residents of long-term care facilities). The competency-related beliefs that our college-age dyads presumably held would have developed through interactions with older individuals, sharing stories and impressions with others, and portrayals of elderly persons in film and advertising (Ruscher, 2001). The degree to which the elderly target met these prior expectations would be a function partly of the specific attributes that described her. Some of these attributes were related to intellectual competence (e.g. wisdom of experience, mind like a steel trap), but others were less so (e.g. moves slowly, liberal). In contrast, the attributes rated in their final impressions uniformly reflected intellectual competence (i.e. slow to learn, forgetful, incompetent, foolish). In retrospect, this imperfect match may in part explain the failure to detect a significant indirect path from closeness to resulting impressions. Time spent talking about a host of stereotypic attributes (i.e. the mediator examined) may not be the ideal path to resulting impressions that were centered around intellectual competency (i.e. the dependent variable examined). Unfortunately, dyads' conversations often blended stereotypic attributes (e.g. 'imagine the old lady drudging around the yard with her cats, while she gives you advice from all her years'), so separating out time spent on competency-related attributes would prove difficult. A better match between the mediator and dependent variable might have facilitated our ability to detect significant mediation.

Unlike the current study, attention (e.g. Fiske \& von Hendy, 1992) and discussion time (e.g. Ruscher \& Duval, 1998) have emerged as mediators of resulting impressions in previous research. The final criterion used for inferring simple mediation often has been that the 
regression coefficient for the independent variable is no longer significant when the mediator is entered in the equation (Baron \& Kenny, 1986). More recently, researchers have included variations on Sobel's test for the significance of the indirect path (Kenny, Kashy, \& Bolger, 1998) or have used empirically derived methods that are less conservative for small sample sizes than Sobel's test (MacKinnon, Lockwood, Hoffman, West, \& Sheets, 2002; Shrout \& Bolger, 2002). Conceivably, mediation via discussion time reported in previous studies may not satisfy contemporary criteria, in which case the current predictions about mediation may have been weakly grounded. Alternatively, the design may have had insufficient power. In addition to the relatively small sample size, the magnitude of the difference between conditions was small (manipulation check on closeness yielded $M \mathrm{~s}=8.12$ and 9.06). A greater difference between the closeness conditions presumably would have increased the direct effect, but also might have increased the magnitude of the indirect effect as well.

\section{Group socialization}

Research on socialization into larger natural social groups is congruent with the present findings. Newcomers to existing groups are taught the appropriate beliefs and behaviors of that group (Moreland \& Levine, 1982). The process of socialization includes leading newcomers to accept consensually held beliefs about outgroups, as well as prescriptions on how to interact with them. For example, in a study of students entering a Canadian military college, members of the Anglophone majority initially held positive or neutral attitudes about various outgroups (e.g. Francophones, immigrants). Over time, however, the individuals who were most socially identified with their ingroup became most negative about outgroups (Guimond, 2000). 'Fitting in' with a group to which one is attracted and identifies with requires, in part, accepting its beliefs about others. Indeed, publicly expressing the beliefs of the group may be perceived as a valuable way of demonstrating early commitment to and attraction for the group. For example, newcomers to university sororities and fraternities (i.e. pledges) express negative prejudice about outgroups primarily when those opinions will be public, but not private; existing members express prejudice equally irrespective of the publicness of those opinions (Noel, Wann, \& Branscombe, 1995; cf. Ryan \& Bogart, 1997).

The present work with dyads in a laboratory setting provides some insight into how prejudices toward and stereotypes about outgroup members may be transmitted during socialization into larger, naturally occurring social groups. When talking about outgroup members, implicitly shared (i.e. stereotypic) attributes most likely should be introduced into the conversation; newcomers who wish to be accepted may find themselves agreeing with and perhaps elaborating on those attributes. Both newcomers and veteran members then may illustrate their viewpoints with stories about specific outgroup members that seemingly illustrate the general qualities of the outgroup (c.f. van Dijk, 1988).

In conclusion, at least at initial acquaintance, people's desire to be liked may lead them to find sources of common ground and shared viewpoints. One of these sources of common ground may, unfortunately, be stereotypic views of outgroup members. Prejudiced individuals therefore may find it exceedingly easy to get along by validating their shared stereotypic beliefs about an outgroup member. Ironically, then, efforts to start off on the right foot with a new acquaintance may come naturally at the expense of a third party.

\section{Acknowledgments}

This research was supported by the Robert E. Flowerree Tulane Psychology Fund. The second and third authors contributed equally to this research, so authorship order was determined by a coin toss. The authors thank Ashley Berg, Allison Bernstein, Morgan Brokaw, Kristi Byers, Sasha Carp, Lynn Cook, Sharon Davidson, Camille Greenberg, Jamie Jaspriza, Jennifer Landeche, and Brooke Sams for their assistance with data collection, coding, and videotape transcription. The authors also thank Scott Reid and the anonymous reviewers for their helpful feedback on an earlier version of the manuscript. 


\section{Note}

1. Percentage of time allocated to discussing stereotypic attributes comprised the number of seconds allocated to stereotypic attributes divided by the sum of the number of seconds allocated to both stereotypic and counterstereotypic attributes. This value provides an indication of relative interest in stereotypic over counterstereotypic attributes. Consequently, for the purposes of testing mediation, we believed that it provided an appropriate indicator of preference for stereotypic attributes.

\section{References}

Allport, G. W. (1954/1989). The nature of prejudice. Reading, MA: Addison-Wesley.

Aron, A., Melinat, E., Aron, E. N., Vallone, R. D., \& Bator, R. J. (1997). The experimental generation of interpersonal closeness: A procedure and some preliminary findings. Personality and Social Psychology Bulletin, 23, 363-377.

Baron, R. M., \& Kenny, D. A. (1986). The moderator-mediator variable distinction in social psychological research: Conceptual, strategic, and statistical considerations. Journal of Personality and Social Psychology, 51, 1173-1182.

Berger, J., Fisek, M. H., Norman, R. Z., \& Zelditch, M. (1977). Status characteristics and social interaction. New York: Elsevier.

Craig, G., \& Duck, S. W. (1977). Similarity, interpersonal attitudes and attraction: The evaluative-descriptive distinction. British Journal of Social and Clinical Psychology, 16, 15-21.

Duval, L. L., Ruscher, J. B., Welsh, K., \& Catanese, S. P. (2000). Bolstering and undercutting use of the elderly stereotype through communication of exemplars: The role of speaker age and exemplar stereotypicality. Basic and Applied Social Psychology, 22, 137-146.

Fein, S., \& Spencer, S. J. (1997). Prejudice as self-image maintenance: Affirming the self through derogating others. Journal of Personality and Social Psychology, 73, 31-44.

Fiske, S. T., \& Neuberg, S. L. (1990). A continuum model of impression formation from category-based to individuating processes: Influence of information and motivation on attention and interpretation. In M. P. Zanna (Ed.), Advances in experimental social psychology (pp. 1-74). New York: Academic Press.

Fiske, S. T., \& von Hendy, H. M. (1992). Personality feedback and situational norms can control stereotyping processes. Journal of Personality and Social Psychology, 62, 577-596.

Guimond, S. (2000). Group socialization and prejudice: The social transmission of intergroup attitudes and beliefs. European Journal of Social Psychology, 30, 335-354.

Harasty, A. S. (1997). The interpersonal nature of social stereotypes: Differential discussion patterns about in-groups and out-groups. Personality and Social Psychology Bulletin, 23, 270-284.

Henderson-King, E. I., \& Nisbett, R. E. (1996). Anti-black prejudice as a function of exposure to the negative behavior of a single black person. Journal of Personality and Social Psychology, 71, 654-664.

Kenny, D. A. (1988). The analysis of data from two-person relationships. In S. Duck \& D. F. Hay (Eds.), Handbook of personal relationships: Theory, research and interventions (pp. 57-77). New York: Wiley.

Kenny, D. A., Kashy, D., \& Bolger, N. (1998). Data analysis in social psychology. In D. T. Gilbert, S. T. Fiske, \& G. Lindzey (Eds.), Handbook of social psychology (4th ed., pp. 233-265). New York: McGraw-Hill

MacKinnon, D. P., Lockwood, C. M., Hoffman, J. M., West, S. G., \& Sheets, V. (2002). A comparison of methods to test mediation and other intervening variable effects. Psychological Methods, 7, 83-104.

Marks, G., \& Miller, N. (1987). Ten years of research on the false consensus effect: An empirical and theoretical review. Psychological Bulletin, 102, 72-90.

McCarthy, B., \& Duck, S. W. (1976). Friendship duration and responses to attitudinal agreement-disagreement. British Journal of Social and Clinical Psychology, 15, 377-386.

Moreland, R. L., \& Levine, J. M. (1982). Socialization in small groups: Temporal changes in individual-group relations. In L. Berkowitz (Ed.), Advances in experimental social psychology (pp. 137-192). New York: Academic Press.

Noel, J. G., Wann, D. L., \& Branscombe, N. R. (1995). Peripheral ingroup membership status and public negativity toward outgroups. Journal of Personality and Social Psychology, 68, 127-137.

O'Farrell, K. J., \& Ruscher, J. B. (2000, February). Close friendship and information processing in response to overhearing self-relevant information. Poster presented at the meeting of the Society of Personality and Social Psychology, Nashville, TN.

Preacher, K. J., \& Hayes, A. F. (2004). SPSS and SAS procedures for estimating indirect effects in simple mediation models. Behavior research methods, instruments, and computers, 36, 717-731. 
Ruscher, J. B. (2001). Prejudiced communication: A social psychological perspective. New York: Guilford.

Ruscher, J. B., \& Duval, L. L. (1998). Multiple communicators with unique target information transmit less stereotypical impressions. Journal of Personality and Social Psychology, 74, 329-344.

Ruscher, J. B., \& Hammer, E. D. (1994). Revising disrupted impressions through conversation. Journal of Personality and Social Psychology, 66, 530-541.

Ruscher, J. B., Hammer, E. Y., \& Hammer, E. D. (1996). Forming shared impressions through conversation: An adaptation of the Continuum Model. Personality and Social Psychology Bulletin, 22, 705-720.

Ruscher, J. B., \& Hurley, M. M. (2000). Off-target verbosity evokes negative stereotypes of older adults. Journal of Language and Social Psychology, 19, 139-147.

Ruscher, J. B., Santuzzi, A. M., \& Hammer, E. Y. (2003). Shared impression formation in the cognitively interdependent dyad. British Journal of Social Psychology, 42, 411-425.

Ryan, C. S., \& Bogart, L. M. (1997). Development of new group members' in-group and out-group stereotypes: Changes in perceived group variability and ethnocentrism. Journal of Personality and Social Psychology, 73, 719-732.

Schaller, M., \& Conway, L. G. (1999). Influence of impression-management goals on the emerging contents of group stereotypes: Support for a social-evolutionary process. Personality and Social Psychology Bulletin, 25, 819-833.

Schaller, M., Conway, L. G., \& Tanchuk, T. L. (2002). Selective pressures on the once and future contents of ethnic stereotypes: Effects of the communicability of traits. Journal of Personality and Social Psychology, 82, 861-877.

Sedikides, C., Campbell, W. K., Reeder, G. D., \& Elliot, A. J. (1999). The relationship closeness induction task. Representative Research in Social Psychology, 23, 1-4.

Shrout, P. E., \& Bolger, N. (2002). Mediation in experimental and nonexperimental studies: New procedures and recommendations. Psychological Methods, 7, 422-445.

Stasser, G., \& Titus, W. (1985). Pooling of unshared information in group decision making: Biased information sampling during discussion. Journal of Personality and Social Psychology, 48, 1467-1478.

Swann, W. B., de la Ronde, C., \& Hixon, J. G. (1998) Authenticity and positivity strivings in marriage and courtship. Journal of Personality and Social Psychology, 66, 857-869. van Dijk, T. A. (1988). How 'they' hit the headlines: Ethnic minorities in the press. In G. Smitherman-Donaldson \& T. A. van Dijk (Eds.), Discourse and discrimination (pp. 221-262). Detroit, MI: Wayne State University Press.

Wittenbaum, G. M., Hubbell, A. P., \& Zuckerman, C. (1999). Mutual enhancement: Toward an understanding of the collective preference for shared information. Journal of Personality and Social Psychology, 77, 967-978.

Wittenbaum, G. M., \& Stasser, G. (1996). Management of information in small groups. In J. L. Nye \& A. M. Brower (Eds.), What's social about social cognition? (pp. 3-28). Thousand Oaks, CA: Sage.

Yost, E. A. (1995, July). The role of motivation and cognitive capacity in transactive impression formation. Poster presented at the meeting of the American Psychological Society, New York.

Zaccaro, S. J., \& McCoy, M. C. (1988). The effects of task and interpersonal cohesiveness on performance of a disjunctive group task. Journal of Applied Social Psychology, 18, 837-851.

Paper received 18 December 2003; revised version accepted 17 January 2005.

\section{Biographical notes}

JANET B. RUSCHER is professor and chair of the Department of Psychology at Tulane University in New Orleans, Louisiana. Her research focuses primarily on stereotyping and prejudice as they are evident in conversation. Summaries of her empirical work on these topics appear in Advances in experimental social psychology (Vol. 30) and are also included in her book, Prejudiced communication: A social psychological perspective.

ELIZABETH L. CRALlEy has an MA in measurement from Illinois State University and a PhD in social psychology from Tulane University. Her experimental research focuses on faceism and bias in the media. She is currently a visiting assistant professor at American University in Washington, D.C.

KIMBERLY J. O'FARRELL has a PhD in social psychology from Tulane University, and is currently an assistant professor at Minnesota State University at Mankato. Her research focuses on the impact of interpersonal feedback on the self. 